\title{
Evaluation of the combustion characteristics of isolated droplets of Jet $A$ blended with ethanol and butanol
}

\author{
Álvaro Muelas, Pilar Remacha, Javier Ballester* \\ Laboratory for Research on Fluid Dynamics and Combustion Technologies (LIFTEC) \\ University of Zaragoza / CSIC, Zaragoza, Spain \\ *Corresponding author: ballester@unizar.es
}

\begin{abstract}
In light of the potential of ethanol and butanol as alternative fuels for blending with conventional kerosene in gas turbine engines, experimental data regarding the burning characteristics of these blends are required in order to better understand their combustion process. In this study, free-falling droplets of Jet A, ethanol, butanol and their mixtures $(20 \%$ alcohol in Jet $A$ by volume) were examined in a combustion chamber which provides representative conditions of real flames, both in terms of temperature and oxygen availability. Results show that the evolution of droplet diameter for Jet $A$ and its blends with both alcohols are very similar, regardless of the obvious compositional differences. On the other hand, sooting behaviors are found to be quite different, with a clear reduction in the sooting propensity of the Jet A/alcohol mixtures when compared to neat kerosene. These results are consistent with previous studies in gas turbines, suggesting that such blends are viable alternative fuels with similar combustion characteristics to Jet $A$, but with much less propensity to produce soot. Moreover, this study provides new results on the combustion properties of Jet $A /$ ethanol and Jet $A / b u t a n o l$ mixtures, for which very scarce data exist in the open literature.
\end{abstract}

\section{Keywords}

Droplet combustion, Jet A, Butanol, Ethanol.

\section{Introduction}

Renewable fuels derived from biofeedstocks (i.e. biofuels) are recently gaining importance due to environmental and sustainability reasons. Biofuels are reported to have negligible sulphur content and to inhibit $\mathrm{PAH}$ and soot formation [1]. Furthermore, the biomass used to produce biofuels is renewable, carbon-neutral and domestically available. Although fossil fuels are likely to remain dominating transportation and energy systems in the near future [2], the use of biofuels as additives can significantly reduce their consumption, and therefore their environmental footprint. The most widely used biofuel today is by far bio-ethanol [1,2], which is commonly added to gasoline for its use in internal combustion engines. Ethanol production via fermentation of plants and starches was among the very first developments in biofuels because of the already well-established alcohol industry [3]. Although ethanol production from edible crops poses serious concerns, such as competition with the food industry or indirect land-use change, it remains nowadays as the major source for bio-ethanol feedstock [2]. These concerns have motivated efforts to find more environmentally-friendly processes for ethanol production, such as lignocellulosic biomass or residual waste conversion (second generation bio-ethanol).

Even though ethanol is the most used biofuel nowadays, some of its properties entail significant limitations. A research on potential new fuel molecules has been carried out in order to overcome these drawbacks. One of the most promising candidates is butanol, which has several well-known advantages when compared with ethanol [28]:

- $\quad$ Higher energy density.

- $\quad$ Lower propensity for water absorption.

- Higher miscibility with hydrocarbons.

- $\quad$ Boiling point closer to the gasoline/diesel fuel range: lesser impact on the fuel distillation curve.

- Better material compatibility: corrosion towards ferrous metals and elastomers swelling are reported to be much less severe than in the case of ethanol.

- $\quad$ Lower vapor pressure: safer manipulation and less volatile organic compounds emission.

- $\quad$ Lower heat of vaporization, which facilitates ignition.

- Current engines can run on more enriched butanol blends without any modification.

Bio-butanol can be both produced by fermentation of edible crops (first generation biofuel) or through more advanced technologies, using lignocellulosic biomass or algae as feedstock (second generation biofuel) [3-5]. 
Although there is currently much less butanol production capacity compared to ethanol, several companies are developing technologies for bio-butanol synthesis, and equipping ethanol plants with butanol production capabilities through cost-effective retrofitting $[4,7]$.

A comparatively large number of studies have analyzed the performance of ethanol and butanol in sparkignition engines, both as pure fuels or blended with gasoline (e.g. [9, 10]). Much less work has been done regarding its possible use in gas turbine engines, even though some recent studies point to the feasibility of kerosene-alcohol mixtures for their use in stationary gas turbines. Mendez et al. investigated Jet A/butanol [7] and Jet A/ethanol [11] mixtures in a $30 \mathrm{~kW}$ experimental gas turbine. Results suggest that blending Jet $A$ with both alcohols is a viable alternative for achieving $\mathrm{CO}$ and NOx emissions reduction while maintaining similar performance to that of pure kerosene. Patra et al. studied the combustion characteristics of kerosene / ethanol mixtures in an experimental axi-symmetric combustor [12], concluding that ethanol addition significantly decreases the flame luminosity due to soot reduction, while also decreasing $\mathrm{CO}$ emissionsi.

Even though engine studies provide very useful information regarding fuel performance under realistic conditions, results can be dependent on several non-controllable variables (e.g. fuel spray patterns, temperature profiles inside the combustion chamber, etc.), and therefore results can depend to some extent on the experimental facility used. On the contrary, in the much more simplified single droplet configuration all the parameters affecting the results are completely known and controllable, and therefore the combustion characteristics observed are intrinsically attributable to the fuel. Recent studies have examined the combustion characteristics of pure ethanol (e.g. [13, 14]) and butanol (e.g. [8, 15]) droplets, but to the authors' knowledge, none has addressed the droplet combustion characteristics of these alcohols blended with conventional kerosene. The main objective of this work is therefore to provide new experimental data on the combustion and sooting characteristics of unsupported, free-falling droplets of ethanol/Jet $A$ and butanol/Jet $A$ blends.

\section{Experimental}

Experiments were conducted in the Droplet Combustion Facility (DCF) developed at LIFTEC and displayed in Figure 1. Details of the facility can be found in a previous work [16], and therefore only the most important features of the experimental method will be explained here.

\section{Droplet combustion facility}

Fuel droplets were generated in the DCF by means of a piezoelectric device with initial diameters $\left(D_{0}\right)$ of 150 $\pm 1.7 \mu \mathrm{m}$ for all the cases studied. This size was chosen because it is considered to be a good compromise between actual sizes in practical applications and a good accuracy of the experimental results. Droplet spacing always exceeded 120 droplet diameters, so that interactions between droplets can be considered to be negligible. As droplet generation stability is perhaps the most critical variable in the experiment, initial droplet diameter was thoroughly checked by means of repeated size measurements at a given location ( $2 \mathrm{~mm}$ after injection), at least at the beginning and end of each test.
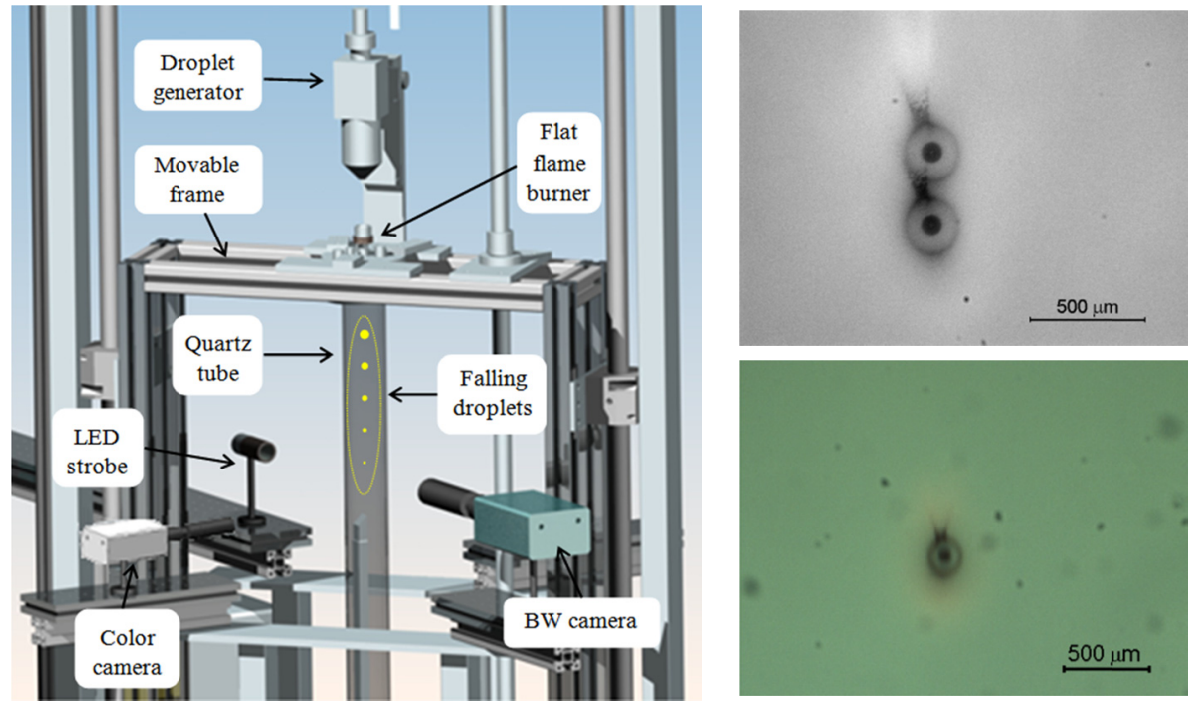

Figure 1. Schematic of the droplet combustion facility (left) and images taken by both cameras for a same droplet (right). 
The monosized droplets were injected along the axis of a quartz tube, coaxially with the combustion products generated by a flat-flame premixed methane-air burner (McKenna). This coflow provided a controllable and realistic environment to study the evolution of fuel droplets under representative conditions of real flames, both in terms of oxygen availability and temperature. As in real flames a droplet might be subjected to different oxygen conditions, the droplet combustion process was studied both at 3 and $10 \%$ of oxygen (by volume, dry basis) in the coflow.

Different imaging methods were used to record visual information describing the various aspects of droplet combustion. Size and velocity evolution of droplets were recorded through a black and white (BW) high sensitivity CCD camera (QImaging Retiga SRV, 12-bit Mono) fitted with a long distance microscope and backlighted via LED strobe. This optical system was programmed to record two sequential shots of a droplet in the same frame with a time lapse of $500 \mu$ s between them. As it can be seen in Figure 1, this imaging method not only gives information about the droplet size and motion, but also about the existence of a soot shell for certain conditions. A color camera (Teledyne DALSA Genie HC1024, 8-bit) perpendicularly placed to the BW camera and faintly backlighted was used to record the flame images. The weak backlight was provided in order to make the droplet distinguishable from the self-illuminated flame, capturing in the same image the free-falling droplet surrounded by its flame, as also shown in Figure 1.

Pictures taken with both imaging methods were post-processed in order to extract the relevant droplet combustion features in the most precise and repeatable way. However, for the fuels and conditions examined in this study, the flames registered in the color images were so weak that the involved uncertainties are considered too high to extract reliable quantitative data.

\section{Fuels investigated}

Commercial Jet A obtained from a local airport, ethanol (99.8\% purity) and 1-butanol (99.4\% purity) were used for the tests. Additionally, two mixtures were prepared with $80 \%$ Jet A and $20 \%$ alcohol by volume, denoted as B20 and E20 for blends of Jet A with butanol and ethanol, respectively. The main properties for the pure fuels are shown in Table 1. Ethanol and butanol properties are extracted from the literature, whereas a specific analysis of the Jet A sample was performed at the Instituto de Carboquímica (ICB-CSIC) in order to obtain its composition and most significant properties.

Table 1. Selective properties of the fuels investigated.

\begin{tabular}{|c|c|c|c|c|c|c|c|c|c|}
\hline & $\begin{array}{l}\text { Molecular } \\
\text { formula }\end{array}$ & $\begin{array}{c}\mathrm{MW} \\
(\mathrm{g} / \mathrm{mol})\end{array}$ & $\begin{array}{c}\% \mathrm{C} \\
\text { (mass) }\end{array}$ & $\begin{array}{c}\% \mathrm{H} \\
\text { (mass) }\end{array}$ & $\begin{array}{c}\% 0 \\
\text { (mass) }\end{array}$ & $\begin{array}{c}\text { Boiling point } \\
\left({ }^{\circ} \mathrm{C}\right)\end{array}$ & $\begin{array}{l}\text { Lower Heating } \\
\text { Value }(\mathrm{MJ} / \mathrm{kg})\end{array}$ & $\begin{array}{l}\text { Density at } \\
20^{\circ} \mathrm{C}\left(\mathrm{kg} / \mathrm{m}^{3}\right)\end{array}$ & $\begin{array}{c}\text { Vaporization } \\
\text { Enthalpy }(\mathrm{kJ} / \mathrm{kg})\end{array}$ \\
\hline Jet $A$ & $\mathrm{C}_{10.6} \mathrm{H}_{19.6}$ & 146.8 & 86.6 & 13.4 & - & $99-286$ & 42.60 & 791 & $330^{a}$ \\
\hline 1-Butanol ${ }^{b}$ & $\mathrm{C}_{4} \mathrm{H}_{10} \mathrm{O}$ & 74.1 & 64.9 & 13.5 & 21.6 & 117 & 33.10 & 810 & 584 \\
\hline Ethanol $^{\mathrm{b}}$ & $\mathrm{C}_{2} \mathrm{H}_{6} \mathrm{O}$ & 46.0 & 52.2 & 13.0 & 34.8 & 78 & 26.95 & 789 & 838 \\
\hline \multicolumn{10}{|c|}{${ }^{\mathrm{a}}$ From ref. [7] } \\
\hline \multicolumn{10}{|c|}{${ }^{b}$ From ref. [17] } \\
\hline
\end{tabular}

\section{Results and discussion}

Droplet size and burning rate evolution

As stated above, tests were performed for Jet A, B20, E20, butanol and ethanol for two different oxygen conditions: 3 and $10 \% \mathrm{O}_{2}$. The normalized droplet size evolutions for these two conditions are shown in Figures $2 a$ and $2 b$ respectively. Based on the quasi-steady theory of droplet burning, measurements are displayed as normalized square diameter versus normalized time. Normalization is performed with the droplet diameter value at injection $\left(D_{0}\right)$. 


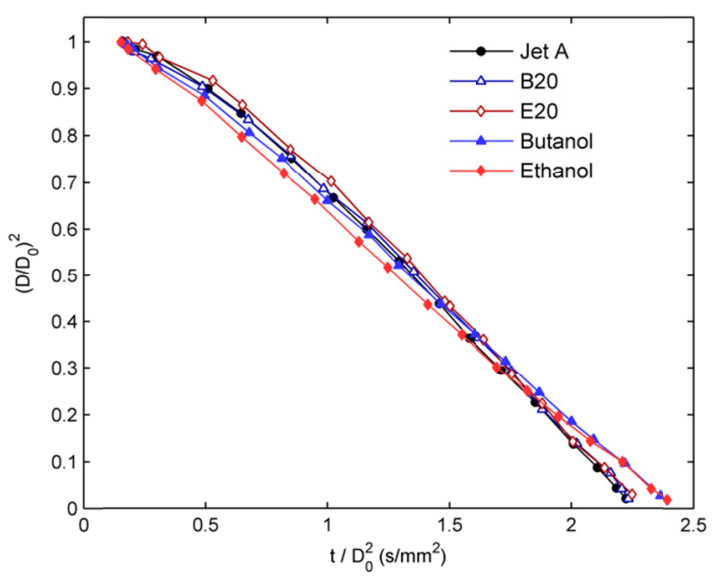

a) $3 \% \mathrm{O}_{2}$

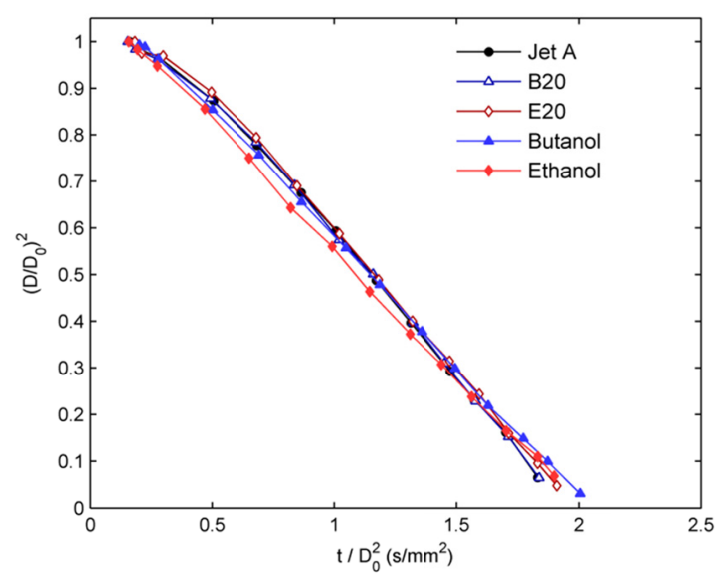

b) $10 \% \mathrm{O}_{2}$

Figure 2. Evolution of normalized droplet size for Jet A, B20, E20, butanol and ethanol for both oxygen conditions studied.

Results displayed in Figure 2 are in good agreement with the ' $\mathrm{d}^{2}$ law', and after a short heat-up period, the normalized square diameter decreases linearly with time with a nearly constant slope (the burning rate $K$ ) for all the cases studied. For each oxygen condition, the observed behaviors are found to be quite similar between fuels, as all of them display close burning rates and droplet consumption times, particularly among Jet A, B20 and E20. Pure alcohols exhibit the most distinctive behaviors, with shorter heat-up periods and smaller burning rates. The lower boiling points of both alcohols compared to most of the Jet A constituents can be responsible for the shorter heat-up periods, whereas their higher latent heats of vaporization could account for the smaller burning rates. Comparing ethanol and butanol, the former appears to show a slightly faster heating period and a lower burning rate, results in accordance with the properties listed in Table 1. On the other hand, E20 and particularly B20 display almost indistinguishable behaviors from pure Jet $A$ throughout all the vaporization process. As both alcohols' boiling points are located at the beginning of the Jet A distillation curve, and the burning rates of the three pure fuels are relatively close, this almost coincident behavior can either imply that there are no preferential vaporizations, or that the similarities between the pure fuels' behavior are masking them. For a certain fuel, it is clear that as oxygen concentration in the coflow increases, so does the burning rate, accelerating substantially the droplet evaporation process. This is ascribed to the higher temperature in the shell flame around the droplet, leading to an enhanced heat transfer to the droplet.

In order to gain insight into the slight differences found between fuels, their burning rates were quantified as the instantaneous slopes of the curves displayed in Figure 2: $K=-d\left(D^{2}\right) / d t$. Since differentiation greatly amplifies any small experimental uncertainty in $D^{2}$ curves, a five-point centred moving average was performed for smoothing purposes. The resulting curves are displayed in Figure 3, where the evolution of $K$ with normalized time is shown. Even though the slopes in Figure 2 seemed practically constant, the calculated burning rates plotted in Figure 3 display clearly unsteady behaviors. The burning rates extracted for Jet A, B20 and E20 continuously increase with time, whereas those of butanol and ethanol show an initial growth followed by a decrease near the final stages of droplet combustion. The initial growth is possibly caused by the droplet heating transient, whilst the final decay could be ascribed to different factors such as flame extinction or the absorption of water vapour by the alcohol droplets. Ambient water vapour absorption was proven to decrease the burning rate of pure ethanol droplets in a recent study [18], mainly in the final stages of droplet combustion. As the droplet environment is rich in water vapour generated in the flat flame burner, this could be indeed a possible reason for the burning rate decay found for ethanol and, to a certain extent, also for butanol (water solubility in 1-butanol is $20 \% \mathrm{w} / \mathrm{w}$ at $20^{\circ} \mathrm{C}$ [17]). As Jet $\mathrm{A}$ is a highly multicomponent fuel, its burning rate variations can be also dependent on fuel composition evolution, complicating therefore its analysis. 


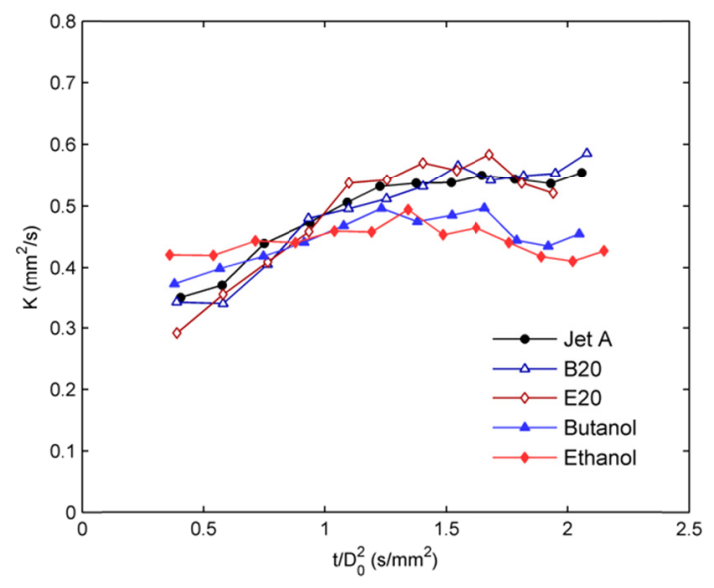

a) $3 \% \mathrm{O}_{2}$

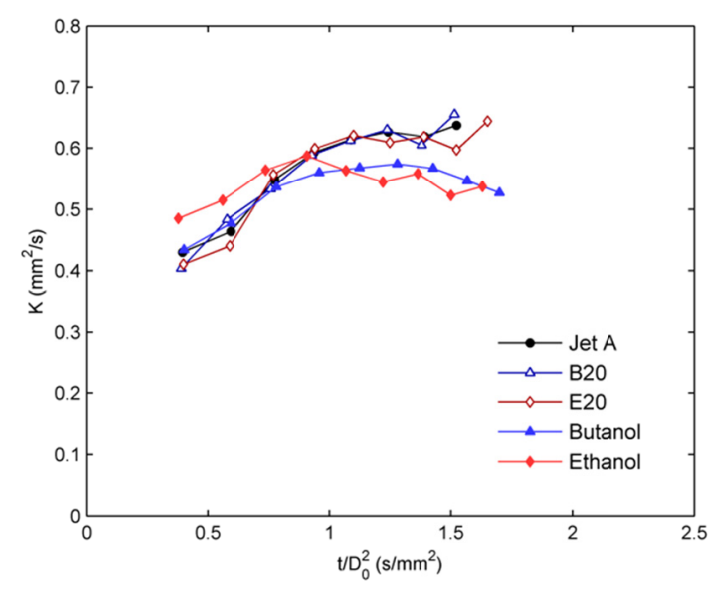

b) $10 \% \mathrm{O}_{2}$

Figure 3. Evolution of burning rate $K\left(\mathrm{~mm}^{2} / \mathrm{s}\right)$ with normalized time for Jet A, B20, E20, butanol and ethanol for both oxygen conditions studied. Five-point centered moving average was performed for smoothing purposes.

\section{$\underline{\text { Soot shell evolution }}$}

Although the droplet size evolutions presented in Figure 2 are found to be quite similar for all the fuels studied, the sooting behaviors differ considerably, as it can be clearly seen in Figure 4, which shows the evolution of soot shells for the $10 \% \mathrm{O}_{2}$ condition. Similar soot shells are usually achieved in totally converction-free environments obtained through microgravity such as [8]. In these configurations, the soot aggregates formed during combustion remain trapped at the radial location where thermophoresis and Stefan flux drag forces balance. Soot shells occurrence is much rarer for free-falling droplets, as the relative velocity between the droplet and the surrounding gases would sweep the soot away. The experimental conditions used in this work provide very low relative velocities between the droplets and the coflow, allowing the formation of an almost perfectly spherical soot shell surrounding the droplets for certain conditions. Even so, as it can be seen in Figure 4, some soot aggregates drifted away from the soot shell due to a small droplet slip velocity, perhaps also with some contribution of buoyancy-induced convection. Conclusions on the evolution and the amount of soot visible around droplets should be therefore taken with caution. However, as droplet velocities are found to be very close among fuels, the authors consider that a qualitative comparison between fuels' sooting propensity can be drawn from their soot shell evolution.

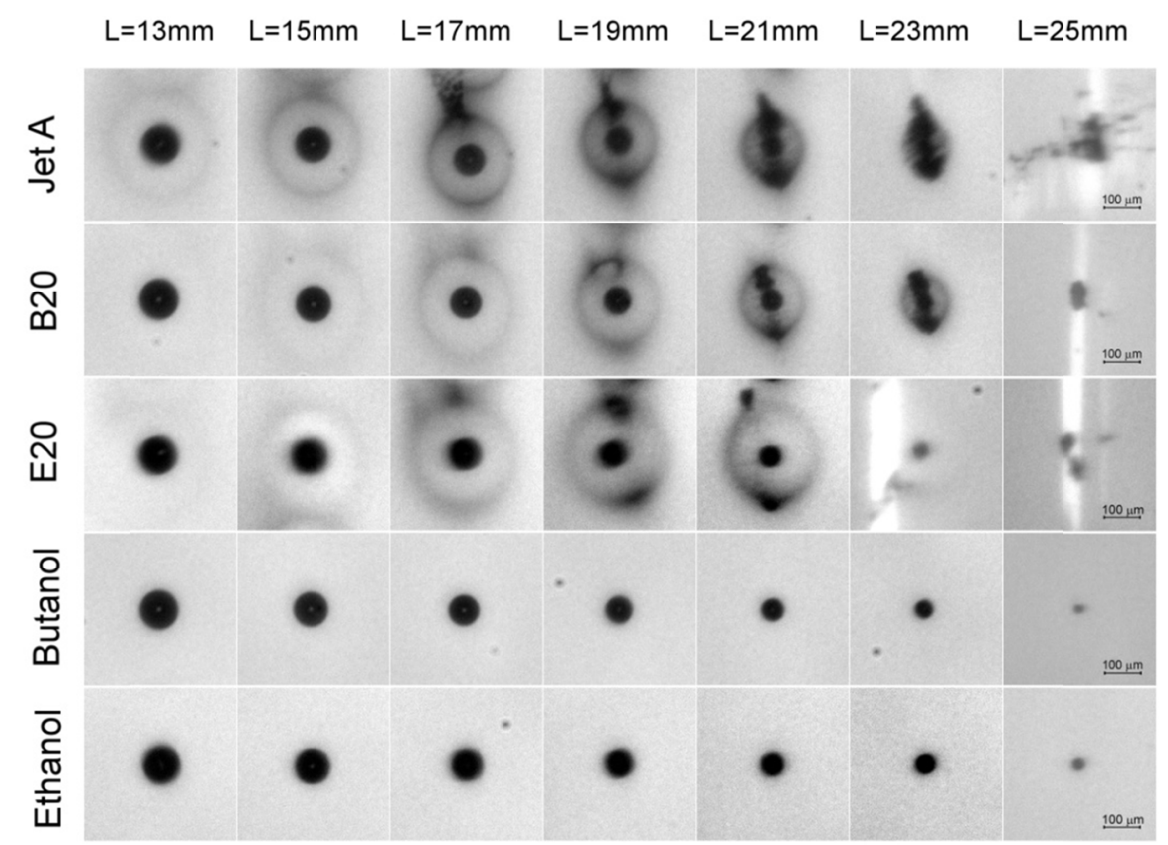

Figure 4. Evolution of droplet and soot shell for the examined fuels (cropped double-exposure BW images).

For a better comparison, pictures are arranged according to their approximate length after injection $(L)$. 
Figure 4 reveals qualitative differences between the soot shells formed for the various fuels, all of them subjected to exactly the same experimental conditions. As expected, no soot shell was found for ethanol and butanol, as no soot was formed. Jet A droplets display perfectly spherical soot shells which become thicker as the droplet combustion proceeds. Near the end of droplet burning, the soot particles agglomerate into a selfsupported crust which completely encloses the droplet, hindering droplet identification (for this reason, some curves in Figure $2 b$ lack a few points at the end of the droplets lifetimes). Droplet depletion occurs with a weak microexplosion, macroscopically visible as a tiny spark at the end of the flame trace. This feature has been reported in other free-falling droplet combustion works (e.g. [13]). B20 and E20 show much thinner soot shells compared to those of pure Jet $\mathrm{A}$, with a significant delay in the soot shell formation and no microexplosion during droplet depletion. These results point to a considerable soot reduction for alcohol blends. B20 displays a more steady behavior, with the soot shell progressively enclosing the droplet, as happened for neat Jet A. On the other hand, E20 produces a soot shell located at a larger radius and with much more unsteady characteristics: the spherical shape eventually breaks, with uneven soot distributions changing continuouslly with time. When the droplet becomes small enough, the wide soot shell quickly oxidizes and breaks down when reaching contact with the receding flame (as happens in the $L=23 \mathrm{~mm}$ picture). After the breakdown, the remaining soot agglomerates continue their burning with the coflow oxygen, their combustion giving a luminous trace.

\section{Visual appearance and analysis of the flame traces}

As the droplet stream falls along the quartz tube, its combustion generates a macroscopically visible flame streak. This streak can provide valuable information regarding the amount of soot present in the flame region, as incandescent soot gives a characteristic yellow luminosity. Therefore, long exposure images of the flame traces were taken with a DSLR camera. Figure 5 shows a comparison of the flame traces captured for all the studied fuels for the $3 \% \mathrm{O}_{2}$ condition.

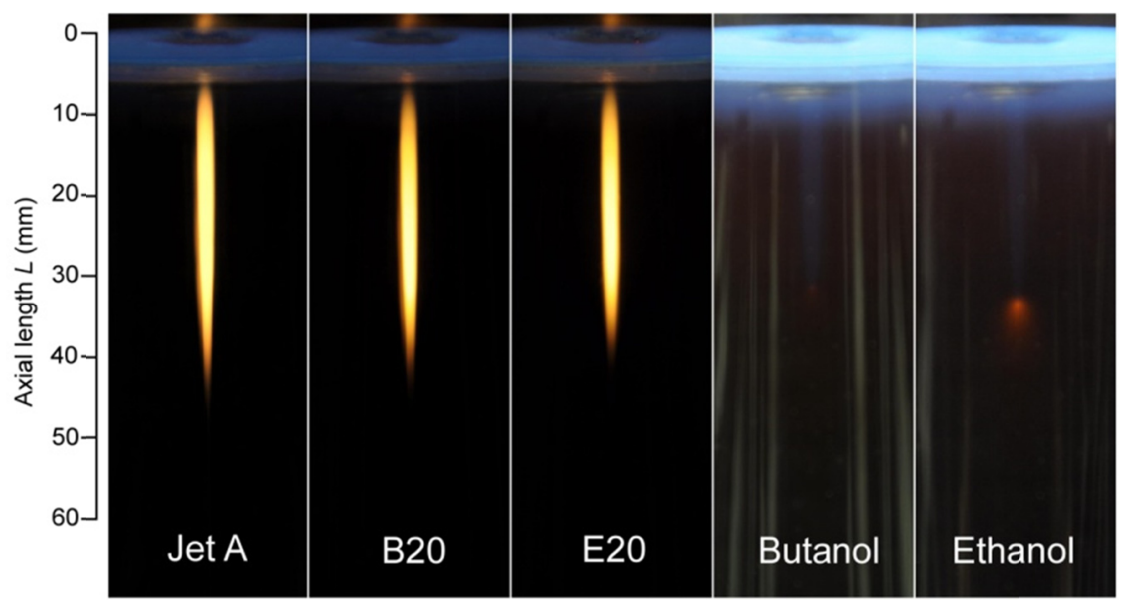

Figure 5. Long exposure photographs for $150 \mu \mathrm{m}$ droplets of different fuels at $3 \% \mathrm{O}_{2}$. The exposure time used for the Jet A, B20 and E20 pictures is $1 / 5 \mathrm{~s}$ ( 5 injected droplets), whereas for both pure alcohols $4 \mathrm{~s}$ (100 injected droplets) were required.

As it can be clearly seen in Figure 5, Jet A, B20 and E20 share the same camera settings, whereas butanol and ethanol required a considerable higher exposure for their bluish traces to appear visible. This is due to the much lower intensity of the chemiluminescence luminosity compared to the black-boidy emission from soot particles. Comparing the flame streaks of Jet A, B20 and E20, it is noted that alcohol addition appears to slightly decrease the flame luminosity within the first millimetres of the trace, where the sooty emission looks somewhat more orangish and less intense. It is noteworthy that these flame traces reach longer axial distances than the droplets themselves (the droplet depletion lengths for the $3 \% \mathrm{O}_{2}$ condition lie between $31 \pm 2 \mathrm{~mm}$ after injection). This is due to the relatively low oxygen availability in the coflow, which lowers the combustion rate of the already formed soot particles. For both alcohols, it is interesting the occurrence of a tiny reddish spot following droplet depletion. This red spot looks much more intense in the ethanol trace, and its origin is unknown, being the emission of external compounds (either present in the original alcohol or absorbed as a contamination) a possible cause. To the authors' knowledge, this feature has not been observed so far in ethanol droplet combustion works, and therefore further work is needed in order to ascertain its cause. 
Since the flame traces for Jet A, B20 and E20 were captured with exactly the same camera settings, a direct comparison of flame brightness can provide a soot propensity indicator for each fuel and condition. Figure 6 shows an analysis of the flame traces displayed in Figure 5. The axial profiles of luminasity were calculated by adding the values at all pixels across a given cross section of the flame trace. Although the quantitative value of this result is unclear (e.g., due to eventual differences in soot temperature), the luminosity curves can be interpreted in terms of the differences in the amount of soot for the various fuels at fixed experimental conditions.

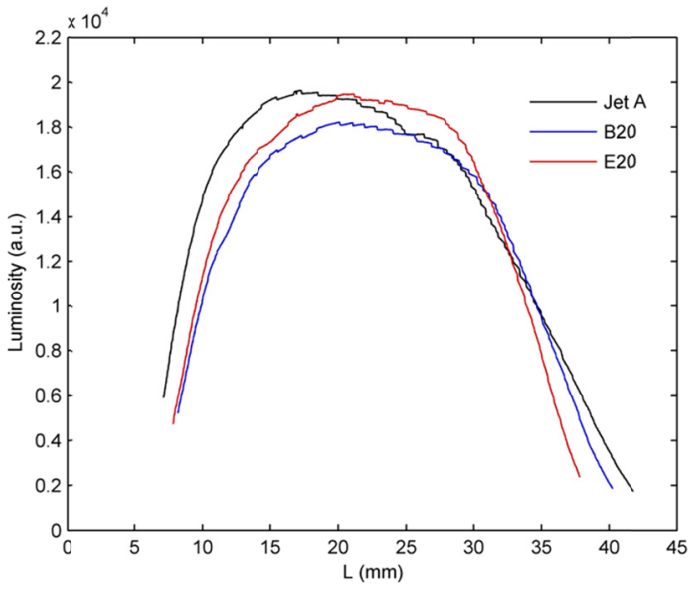

Figure 6. Axial variation of the flame traces' luminosity for $150 \mu \mathrm{m}$ droplets off Jet $\mathrm{A}, \mathrm{B} 20$ and $\mathrm{E} 20$ for the $3 \% \mathrm{O}_{2}$ condition in the coflow.

Figure 6 illustrates in more quantitative terms the differences in the visual aspect of flame traces noted above. Within the first millimetres, B20 and E20 traces are less luminous than that of Jet A, as the luminosity profiles of these two mixtures are slightly shifted to the right. This could imply a preferential vaporization of the more volatile alcohols in the first region, although this result was not observed in the droplet size evolutions presented in Figure 2 (maybe as a consequence of the similar behaviors in the droplet evaporation process among fuels). While the B20 luminosity profile remains below that of pure Jet $A$ for the whole trace length, the E20 trace surpasses the Jet A luminosity for axial distances comprised between $L \sim 20$ and $L \sim 31 \mathrm{~mm}$ (which is approx. the droplet consumption length). This could be ascribed to the unstable behavior of the E20 mixture in this last stage, as it was stated above for the $10 \% \mathrm{O}_{2}$ condition. In this region, the E20 flame trace becomes slightlly wider than the rest, analogously to the wider soot shells found in Figure 4. This greater soot dispersion for the E20 trace could enhance soot consumption within this region, justifying the higher luminosity prior to droplet depletion and the shorter flame trace recorded afterwards. The integration along the axial coordinate of the whole luminosity profiles displayed in Figure 6 yields a reduction of $10.8 \%$ in luminosity for the B20 and a $9.1 \%$ reduction for the E20 when compared to the pure Jet $\mathrm{A}$ trace.

\section{Conclusions}

The droplet combustion characteristics of Jet A, ethanol, butanol, E20 and B20 were studied under the same experimental conditions, which are thought to be representative of temperature and oxygen availability in real flames. In addition, relative velocities between droplets and the surrounding gases were minimized, so that droplets burnt in a practically 1-D configuration, as proven by the formation of almost perfectly spherical soot shells. As a consequence, the obtained experimental results may be compared with theoretical one-dimensional droplet combustion models. All the droplet combustion curves are in good agreement with the $d^{2}$ law after the initial heat up period. The B20 and E20 mixtures show very close burning rates to pure Jet A throughout all the combustion process, whereas pure alcohols display a slightly different behavior, with a noticeable burning rate reduction for the latter stages of droplet combustion. This could be ascribed to vapour water absorption by the hydrophilic alcohol droplets, although further work would be needed to corroborate or discard this hypothesis. The most significant combustion characteristic of Jet A/alcohol mixtures was found to be their lower soot formation tendency. This was consistently demonstrated through the close-up images of the soot shells and the lower luminosity of the visible flame traces. The strong similarities in combustion rates between pure Jet $A$ and its mixtures with butanol and ethanol, in addition to the lower propensity to form soot of the latter support the potential of both alcohols as attractive additives to Jet A. 


\section{Acknowledgements}

This work was supported by the Spanish Ministry of Education through the pre-doctoral grant FPU15/01866 and the Ministry of Science and Innovation through the research projects CSD2010-00011 and ENE2016-76436-R. The analysis of the Jet A sample was kindly provided by Drs. R. Murillo and M. Callen, from the Instituto de Carboquímica (ICB-CSIC). The authors are also grateful to Dr. Álvaro Sobrino for his assistance with data capture and analysis, and to Luis Ojeda for his support in the experimental tasks. The work of Mario Angeloni in the development of the Droplet Combustion Facility, without which this study would not have been possible, is also gratefully acknowledged.

\section{References}

[1] Saxena, R., Adhikari, D., and Goyal, H., 2009, Renewable and Sustainable Energy Reviews, 13(1), pp. 167178.

[2] Sarathy, S. M., Oßwald, P., Hansen, N., and Kohse-Höinghaus, K., 2014, Progress in Energy and Combustion Science, 44, pp. 40-102.

[3] Bergthorson, J. M., and Thomson, M. J., 2015, Renewable and Sustainable Energy Reviews, 42, pp. 13931417.

[4] Jin, C., Yao, M., Liu, H., Chia-fon, F. L., and Ji, J., 2011, Renewable and Sustainable Energy Reviews, 15(8), pp. 4080-4106.

[5] Bruno, T. J., Wolk, A., and Naydich, A., 2009, Energy \& Fuels, 23(4), pp. 2295-2306.

[6] Hoxie, A., Schoo, R., and Braden, J., 2014, Fuel, 120, pp. 22-29.

[7] Mendez, C., Parthasarathy, R., and Gollahalli, S., 2014, Applied Energy, 118, pp. 135-140.

[8] Xu, Y., and Avedisian, C. T., 2015, Energy \& Fuels, 29(5), pp. 3467-3475.

[9] Galloni, E., Fontana, G., Staccone, S., and Scala, F., 2016, Energy Conversion and Management, 110, pp. 319-326.

[10] Zhang, Z., et al., 2014, Fuel, 130, pp. 177-188.

[11] Mendez, C., Parthasarathy, R., and Gollahalli, S., 2012, 50th AIAA Aerospace Sciences Meeting including the New Horizons Forum and Aerospace Exposition, pp. 522.

[12] Patra, J., et al., 2015, Fuel, 144, pp. 205-213.

[13] Botero, M., Huang, Y., Zhu, D., Molina, A., and Law, C., 2012, Fuel, 94, pp. 342-347.

[14] Nakaya, S., Segawa, D., Kadota, T., Nagashima, Y., and Furuta, T., 2011, Proceedings of the Combustion Institute, 33(2), pp. 2031-2038.

[15] Alam, F. E., Liu, Y., Avedisian, C., Dryer, F., and Farouk, T., 2015, Proceedings of the Combustion Institute, 35(2), pp. 1693-1700.

[16] Angeloni, M., Remacha, P., Martínez, A., and Ballester, J., 2016, Fuel, 184, pp. 889-895.

[17] National Institute of Standards and Technology, http://webbook.nist.gov/. ([cit. 2017-03-08]).

[18] Saharin, S., et al., 2011, ASME 2011 Turbo Expo: Turbine Technical Conference and Exposition, pp. 669676. 